\title{
An Analysis Of The Strategic Effect Of Lnformation System On The Lmmunity Enhancement Of Gallbladder Patients
}

\author{
Seong-Ran Lee ${ }^{1^{*}}$ \\ ${ }^{1 *}$ Department of Medical Information, Kongju National University, Chungnam, Republic of Korea, \\ leesr@kongju.ac.kr ${ }^{1}$
}

Article History: Received: 11 January 2021; Accepted: 27 February 2021; Published online: 5 April 2021

\begin{abstract}
This paper is to conduct a strategic analysis of the information system to improve the immunity system of gallbladder cancer patients. The subjects of the study were 146 people who visited internal medicine clinics located in Chungcheong Province from March 11 to May 13, 2019. The group of people who mediated the information system was classified as 53 people and those who did not mediated the information system were classified as 53 people. The change in patient condition was analyzed as t-test following the application of the information system. The application of the body's immune system to the information system was measured at 4, 8, 12, 16, 20 and 24 weeks. The results of this study are as follows. First, LDL, a bad cholesterol decreased significantly after the information system was applied( $\mathrm{t}=3.72, \mathrm{p}<.05)$. Second, the physical immunity continued to increase after the application of the information system. However, the body's immunity has tended to decline since the 16th. Therefore, to prevent the incidence of gallbladder cancer, diet management such as greasy and meat diet is required.
\end{abstract}

Keywords: information system, immunity, Enhancement, Gallbladder patient

\section{Lntroduction}

Gallbladder cancer is a mass of cancer cells in the gallbladder. Gallbladder cancer is called bad cancer along with pancreatic cancer and bile duct cancer [1],[2],[3]. It usually occurs more in women than in men and is often accompanied by cholelithiasis in $85 \%$ of patients. Gallbladder cancer is difficult to recognize and is often found in the 3rd and 4th stages of diagnosis [4],[5],[6], lt is one of the most careful cancers because the prognosis for treatment is not good. Gallbladder cancer caused by a combination of environmental and genetic factors [7],[8]. 1t is also a risk of recurrence and metastasis after surgery, so people should be careful.

The side effects of cancer treatment vary from person to person. The treatment of gallbladder cancer usually weakens the immune system as well. Immunity works to kill or neutralize pathogens against infection or cancer. People should increase people's immune system through people's usual lifestyle and food control, as people may be worried about the virus' health [9],[17]. We need to find ways to boost our immune system. To that end, we are looking for a strategy to improve our immune system through the application of the information system. In the preceding study, there is a study of gallbladder cancer. However, research on immunity is insufficient [10],[11],[16].

Therefore, this study analyzes the strategic effectiveness of the information system to enhance the immune of gallbladder cancer patients. Through the application of this information system, we aim to improve the efficiency and quality of life of the system to enhance patient satisfaction.

\section{Materials and Methods}

2.1 Design of Information System for Strengthening Immunity

Figure 1 shows the strategic design of the information system for enhancing immunity of gallbladder cancer patients. The steps for building a new information system are as follows : Reliability, efficiency, connection, automation, cost, convenience and speed.

\subsection{Materials and Methods}

The subjects of the study were 146 people who visited internal medicine clinics located in Chungcheong Province from March 11 to May 13, 2019. The group of people who mediated the information system was classified as 53 people and those who did not mediated the information system were classified as 53 people. Basic information was performed in chi-square test. The data were surveyed and interviewed. The change in patient condition was analyzed as t-test following the application of the information system. The application of the body's immune system to the information system was measured at $4,8,12,16,20$ and 24 weeks. 


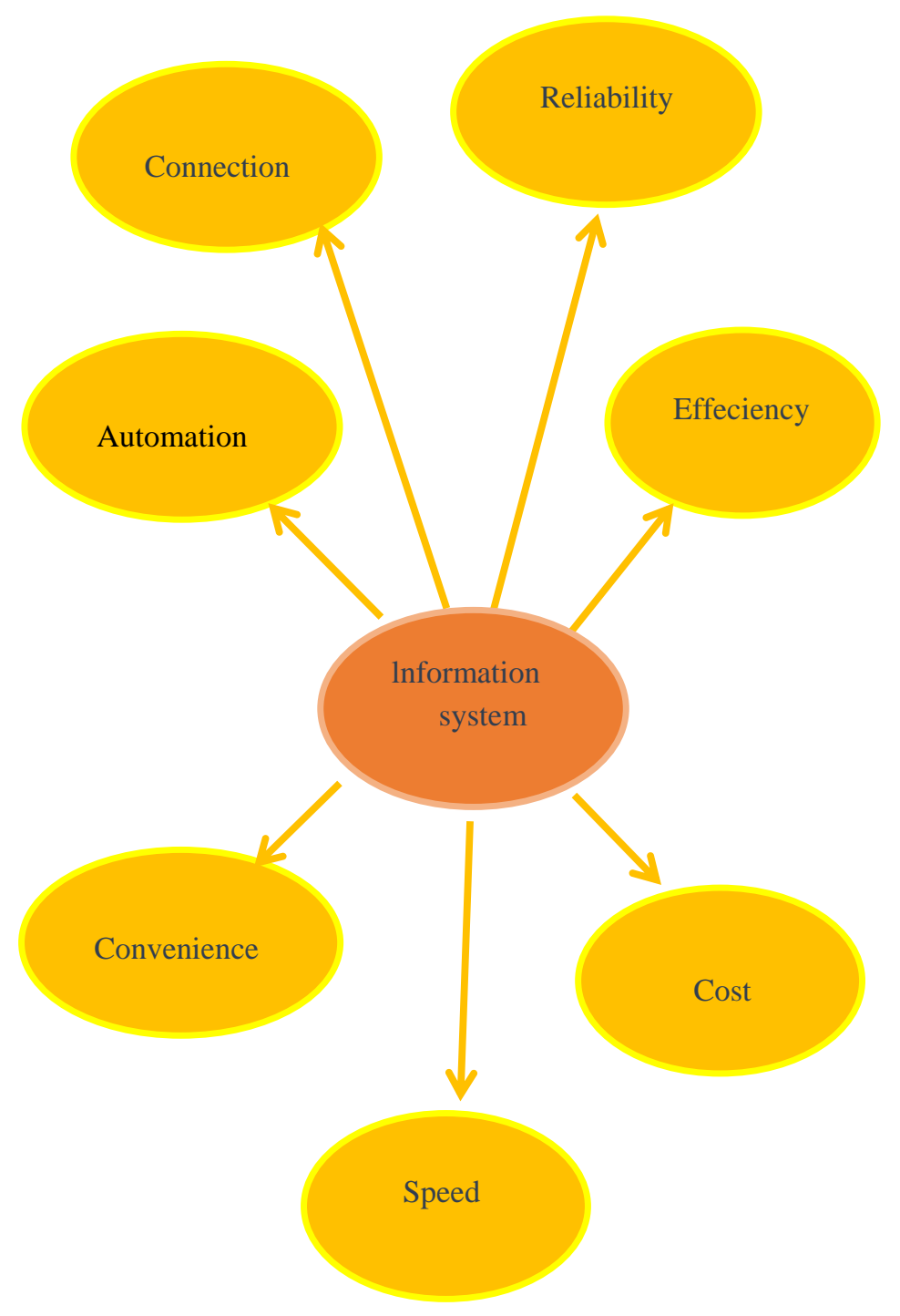

Fig. 1 Strengthening Immunity in Patients with Gallbladder Cancer

\section{Result}

3.1 Basic lnformation of Respondents

Table 1 shows the basic information of the respondents. $39.6 \%$ of experimental group eat meat more frequently than $26.4 \%$ of the control group. Regular exercise showed that $37.7 \%$ of the control group were significantly higher than $22.6 \%$ of the experimental group $\left(X^{2}=1.69, \mathrm{p}<.05\right)$.

Table 1. Basic lnformation of Respondents

\begin{tabular}{|c|l|l|c|}
\hline \multirow{2}{*}{ Variables } & Experi group.. & $\begin{array}{c}\text { Control } \\
\text { group }\end{array}$ & \multirow{2}{*}{$\mathbf{X}^{\mathbf{2}}$} \\
\cline { 2 - 3 } & $\mathbf{N}(\%)$ & $\mathbf{N}(\%)$ & \\
\hline Carnivorous intake & & & \\
\hline Frequently & $21(39.6)$ & $14(26,4)$ & 4.85 \\
\hline Sometimes & $32(60.4)$ & $39(73.6)$ & \\
\hline Regular exercise & & & \\
\hline Yes & $12(22.6)$ & $20(37.7)$ & $1.69^{*}$ \\
\hline No & $41(77.4)$ & $33(62.3)$ & \\
\hline Age/years & & & \\
\hline
\end{tabular}




\begin{tabular}{|l|l|l|l|}
\hline$<49$ & $7(13.2)$ & $14(19.7)$ & 10.72 \\
\hline $50-59$ & $11(20.8)$ & $12(16.9)$ & \\
\hline $60-69$ & $19(35.8)$ & $20(28.2)$ & \\
\hline$\geq 70$ & $16(30.2)$ & $25(35.2)$ & \\
\hline Alcohol drinking & & & \\
\hline Frequently & $23(43.4)$ & $20(28.2)$ & $3.15^{*}$ \\
\hline Non-drinking & $30(56.6)$ & $51(71.8)$ & \\
\hline Marriage status & & & \\
\hline Single & $23(32.4)$ & $16(30.2)$ & 1.38 \\
\hline Married & $48(67.6)$ & $37(69.8)$ & \\
\hline BMI $\left(\mathrm{kg} / \mathrm{m}^{2}\right)$ & & & 7.24 \\
\hline$<18.5$ & $15(28.3)$ & $19(35.8)$ & \\
\hline $18.5-24.9$ & $11(20.8)$ & $9(17.0)$ & \\
\hline$\geq 25$ & $27(50.9)$ & $25(47.2)$ & \\
\hline Total & $53(100.0)$ & $53(100.0)$ & \\
\hline
\end{tabular}

3.2 Comparison of Patient Conditions After lnformation System Application

Table 2 compares the patient's condition before and after the information system intervention. LDL, a bad cholesterol, decreased significantly after the information system was applied $(\mathrm{t}=3.72, \mathrm{p}<.05)$. Fat intake was significantly reduced after application than by the information system $(\mathrm{t}=4.93, \mathrm{p}<.05)$.

Table 2 Comparison of Patient Conditions After lnformation System Application

\begin{tabular}{|c|c|c|c|}
\hline \multirow{2}{*}{$\begin{array}{c}\text { Variables } \\
\text { cholesterol }\end{array}$} & Before & After & \multirow{2}{*}{ ( } \\
\cline { 2 - 4 } & $51.18 \pm 3.26$ & $39.62 \pm 3.64$ & $3.72 *$ \\
\hline Hypertension & $47.92 \pm 0.85$ & $41.57 \pm 0.31$ & 6.18 \\
\hline BMl & $43.84 \pm 1.63$ & $39.62 \pm 1.59$ & 1.54 \\
\hline Fat intake & $46.16 \pm 3.48$ & $35.19 \pm 2.82$ & \\
\hline Sugar intake & $44.27 \pm 0.29$ & $38.47 \pm 0.65$ & $4.93 *$ \\
\hline $\begin{array}{c}\text { Abdominal } \\
\text { pain }\end{array}$ & $35.12 \pm 4.58$ & $23.65 \pm 3.41$ & 1.61 \\
\hline Nausea & $27.54 \pm 0.36$ & $19.47 \pm 0.53$ & 2.86 \\
\hline $\begin{array}{c}\text { Dizziness } \\
\text { reccurence }\end{array}$ & $31.07 \pm 1.47$ & $25.41 \pm 3.74$ & - \\
\hline Immunity & $23.31 \pm 2.94$ & $35.47 \pm 3.63$ & 1.72 \\
\hline Diarrhea & $23.11 \pm 3.52$ & $18.26 \pm 1.59$ & 5.38 \\
\hline Cancer & $15.78 \pm 0.37$ & $12.51 \pm 4.27$ & 2.94 \\
\hline & & & \\
\hline & & & \\
\hline & & & \\
\hline
\end{tabular}


3.3 Before and after the application of the information system of the body's immune system

Figure 2 shows a comparison of before and after the application of the information system of the body's immune system. The physical immunity continued to increase after the application of the information system. However, the body's immunity has tended to decline since the 16 th.

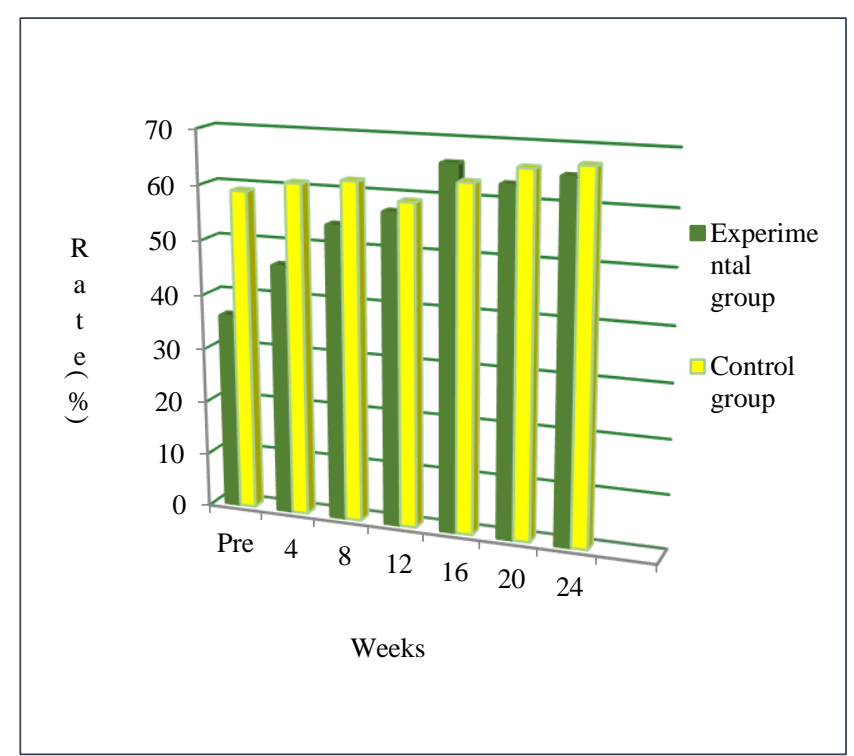

Fig. 2 Application of the lnformation System of the Body's lmmune System

\section{Discussion}

This study aims to measure the effectiveness of information systems to strengthen immunity in patients with gallbladder cancer. As a result of this study, cholesterol has been significantly reduced since the application of the information system. This is consistent with bile duct cancer studied in previous studies [12],[13]. Bile is made up of three components: cholesterol, fatty acid, and bile salt. After gallbladder resection due to gallbladder cancer, each tissue and organ of the body plays its own role, so life is maintained.

Gallbladder is especially necessary to manage properly because the cause of LDL cholesterol is high. If people have cholelithiasis, they have a much higher incidence of gallbladder cancer. It's better to prevent gallbladder cancer through regular checkups [14],[15]. To prevent the recurrence of gallbladder cancer, diet management such as greasy and meat diet is required.

The limitation of this study was for patients who visited the internal medicine department of a general hospital. Therefore, there is a limit to the generalization of the results. However, these results confirm that the application of the information system is effective in reducing gallbladder cancer incidence

\section{Conclusion}

This study analyzes the strategic effectiveness of the information system to enhance the immune of gallbladder cancer patients. The results of this study are as follows.. First, LDL, a bad cholesterol decreased significantly after the information system was applied $(\mathrm{t}=3.72, \mathrm{p}<.05)$. Second, the physical immunity continued to increase after the application of the information system. However, the body's immunity has tended to decline since the 16th. Therefore, to prevent the incidence of gallbladder cancer, diet management such as greasy and meat diet is required.

\section{References}

1. Miltenburg, D. M., Schaffer, R., Breslin, T., and Brandt, M. L. (2000). Changing lndications for Pediatric Cholecystectomy, Pediatrics, 105(1), 1250-3, 2000.

2. Walker, S. K., Maki., A. C., Cannon, R. M., Foley, D. S., Wilson, K. M., and Galganski, L., A. (2013), Etiology and lncidence of Pediatric Gallbladder Disease, Surgery, 154, 927-31.

3. Mehta, S., Lopez, M. E., Chumpitazi, B. P., Mazziotti, M. V., Brandt, M. L. and Fishman, D. S. (2012), Clinical Haracteristics and Risk Factors for Symptomatic Pediatric Gallbladder Disease, Pediatrics, 129, $82-8$,

4. Richards, D. M., Heel, R. C., Brogden, R. N., Speight, T. M. and. Avery, G. S. (2004), A Review of lts Antibacterial Activity, Pharmacological Properties and Therapeutic Use, Drugs, 27, 469-527. 
5. Schaad, U. B., Wedgwood-Krucko, J., and Tschaeppeler, H. (2008), Reversibe Ceftriaxone- Associated Biliary Pseudolithiasis in Children, Lancet, 2, 1411-3.

6. Schaad, U., B., Tschäppeler., H., and Lentze, M. J. (2006), Transient Formation of Precipitations in the Gallbladder Associated with Ceftriaxone Therapy, Pediatr Infect Dis, . 5, 708-10..

7. Shiffman, M. L., Keith, F. B., and Moore, E. W. (2002), Pathogenesis of Ceftriaxone- Associated Biliary Sludge. In Vitro Studies of Calcium-Ceftriaxone Binding and Solubility, Gastroenterology, 99, 1772-8. 8.

8. Palanduz, A., Yalcin, 1., Tonguç, E., Güler, N., Oneş, U.,, and Salman, N. (2000), Sonographic Assessment of Ceftriaxone-Associated Biliary Pseudolithiasis in Children, J Clin Ultrasound, 28, 166-8 9.

9. T. Goetze and Paolucci, (2006), Does Laparoscopy Worsen the Prognosis for Incidental Gallbladder Cancer?, Surg Endosc. 20(2):286-93.

10. Jemal A., Siegel, R., Ward, E., Murray, T. and Xu, C. (2006). Smigal, Cancer statistics. 56(2): 106-30.

11. Mekeel, K. L., and Hemming, A. W. (2007), Surgical Management of Gallbladder Carcinoma: A Review, J Gastrointest Surg. 11:1188-93.

12. Chan, C. P., Chang, H. C., Chen, C. Y., Yang, L. H., Chen, S. T., and Kuo., S. J. (2003), A 10-year Experience of Unsuspected Gallbladder Cancer After Laparoscopic Cholecystectomy, Int Surg, 88:175-9.

13. Misra, S., Chaturvedi., A., Misra, N. C., and Sharma, L. D. (2003), Carcinoma of the Gallbladder, Lancet Oncol. 4:167-76.

14. Muratore, A., Polastri, R., Bouzari, H., Vergara, V., and Capussotti, L. (2000), Radical Surgery for Gallbladder Cancer: A Worthwhile Operation?, Eur J Surg Oncol, 26:160-3

15. Sean, P., Cleary, Laura, A., Dawson, Jennifer, J., and Gallinger, S., (2007). Cancer of the Gallbladder and Extrahepatic Bile Ducts, Current Problems in Surgery, 44(7):396-482.

16. Čančar, E. (2018). Social Media and Everyday Politics; Tim Highfield. Croatian International Relations Review, 24(82), 142-145.

17. Deshko, L. (2018). Application of legal entities to the European Court of Human Rights: a significant disadvantage as the condition of admissibility. Croatian International Relations Review, 24(83), 84-103. 